\title{
EFEKTIVITAS LATIHAN KEGEL DALAM PENURUNAN KEJADIAN INKONTINENSIA URIN PADA LANSIA DI UNIT PELAYANAN SOSIAL LANSIA PURBO YUWONO KLAMPOK BREBES
}

\author{
Uswatun Insani* , Evi Supriatun** , Ani Ratnaningsih*** \\ *) STIKes Bhakti Mandala Husada Slawi, Jalan Cut Nyak Dien No.16, Kalisapu, Slawi, Griya \\ Prajamukti, Kalisapu, Slawi, Tegal, Jawa Tengah 52416, email: uswatun_insani@yahoo.co.id \\ **) STIKes Bhakti Mandala Husada Slawi, Jalan Cut Nyak Dien No.16, Kalisapu, Slawi, Griya \\ Prajamukti, Kalisapu, Slawi, Tegal, Jawa Tengah 52416 \\ ***) STIKes Bhakti Mandala Husada Slawi, Jalan Cut Nyak Dien No.16, Kalisapu, Slawi, Griya \\ Prajamukti, Kalisapu, Slawi, Tegal, Jawa Tengah 52416 \\ Corresponding Author: Uswatun Insani
}

\begin{abstract}
Abstrak
Dampak proses menua pada lansia diantaranya inkontinensia urin. Pada studi pendahuluan, sebagian besar dari lansia $(87,5 \%)$ mengakui kadang sering mengalami inkontinensia urin, 10 lansia $(12,5 \%)$ memiliki ketergantungan penuh. Desain penelitian ini adalah eksperimen kuasi menguji pengaruh latihan Kegel terhadap kejadian inkontinensia pada lansia. Populasinya semua lansia usia $\geq 60$ tahun yang tinggal di Panti Purboyuwono Klampok, Brebes. Sampel merupakan lansia yang masih memiliki tingkat kognitif baik dan bisa melaksanakan aktivitas secara mandiri. Jumlah sampel yakni 38 orang. Uji inferensial yang dipakai dengan menggunakan uji paired $t$ test. Interpretasi dilakukan dengan membandingkan nilai $\mathrm{p}$ dengan nilai alpha $(\alpha=0.05)$. Bila nilai $\mathrm{p} \leq \alpha$, maka keputusannya Ha diterima sedangkan bila nilai $\mathrm{p}>\alpha$, maka keputusannya Ha ditolak. Distribusi lansia dalam kemampuan pengontrolan eliminasi urin sebelum latihan Kegel : tidak dapat 25 lansia $(65,79 \%)$, jarang 4 lansia (10,53\%), kadang-kadang 8 lansia $(21,05 \%)$, dan sering 1 lansia (2,63\%). Adapun distribusi lansia dalam kemampuan pengontrolan eliminasi urin setelah latihan Kegel : jarang 2 lansia (5,26\%), kadang-kadang 12 lansia (31,58\%), dan sering 24 lansia $(63,16 \%)$. Uji statistik one group sample paired t-test menunjukkan signifikansi 0.000 . Nilai signifikansi $0.000 \leq 0.05$, sehingga Ha diterima. Latihan Kegel dilakukan selama 28 hari, 33 orang $(86,84 \%)$ melaporkan adanya penurunan keluhan inkontinensia. Uji statistik didapatkan hasil adanya pengaruh latihan Kegel terhadap penurunan terjadinya inkontinensia urin pada lansia di Panti Wreda Purbo Yuwono Brebes. Penelitian selanjutnya dapat melakukan penelitian inkontinensia urin pada lansia di setting keluarga agar dapat mengetahui faktor lain dapat meningkatkan efektivitas latihan Kegel terhadap inkontinensia urin. Selain itu, penelitian selanjutnya dapat melakukan intervensi latihan Kegel dalam waktu yang lebih lama lagi.
\end{abstract}

Kata kunci : Latihan Kegel, Inkontinensia Urin, Lansia

Insani, U., Supriatun, E., \& Ratnaningsih, A. / Efektivitas latihan Kegel dalam penurunan... Hal 21 dari 57 
Jurnal IImu Keperawatan Medial Bedah 1 (2), Desember 2018, 1-57

ISSN 2338-2058 (print), ISSN 2621-2986 (online)

\section{PENDAHULUAN}

Lanjut usia (lansia) merupakan tahap akhir dari siklus kehidupan manusia, dimana lansia mengalami proses berkurangnya daya tahan tubuh dalam menghadapi rangsangan dari dalam maupun dari luar (Nugroho, 2008). Perubahan yang terjadi pada hampir seluruh organ tubuh, termasuk organ berkemih adalah dampak dari proses menua, lemahnya otot dasar panggul yang menyangga kandung kemih dan sfringter uretra, timbulnya kontraksi yang tidak terkontrol pada kandung kemih yang menimbulkan rangsangan untuk berkemih sebelum waktunya dan pengosongan kandung kemih yang tidak sempurna. Semua hal ini dapat menyebabkan gangguan eliminasi urin (inkontinensia urin) (Nursalam, 2008). Inkontinensia seringkali menyebabkan pasien dan keluarganya frustasi bahkan depresi. Bau yang tidak sedap dan perasan kotor, tentu akan menimbulkan masalah sosial dan psikologis. Selain itu inkontinensia urin juga menganggu aktivitas fisik, seksual dan dehidrasi. Kebanyakan lansia yang mengalami hal ini akan mengurangi minumnya karena dikhawatirkan ngompol. Masalah lain yang dapat ditemukan adalah dekubitus dan infeksi saluran kemih yang berulang, disamping dibutuhkan biaya perawatan sehari-hari yang relatif lebih tinggi untuk keperluan membeli tampon (Setiati, 2001).

Inkontinensia urin pada lanjut usia menduduki urutan ke lima. Berdasarkan penelitian menyebutkan bahwa $15-30 \%$ orang yang tinggal di masyarakat dan $50 \%$ orang yang dirawat di tempat pelayanan kesehatan menderita inkontinensia urin (Pranarka, 2001). Studi pendahuluan yang dilakukan tim peneliti, didapatkan sejumlah 80 lansia yang tinggal di Unit Pelayanan Sosial Lansia Purbo Yuwono memiliki resiko mengalami masalah incontinensia urin. Sebagian besar dari lansia (87,5\%), masih memiliki tingkat kognitif bagus dan masih bisa melaksanakan aktivitas dengan mandiri. Mereka mengakui kadang sering mengalami beser, mengingat musim dingin dan sisanya, sekitar 10 lansia (12,5\%) memiliki ketergantungan penuh dan sudah bedrest total.

Inkontinensia urin adalah pengeluaran urin tanpa disadari dalam jumlah dan frekuensi yang cukup sehingga mengakibatkan masalah gangguan kesehatan dan sosial. Variasi dari inkontinensia urin dapat berupa pengeluaran urin yang terkadang hanya beberapa tetes atau sebaliknya benar-benar banyak. Lansia akan sering berkemih pada malam hari dan frekuensi berkemih meningkat akibat kehilangan kontraktibilitas dan kelemahan dari tonus otot kandung kemih. Peningkatan sisa urin dalam kandung kemih, kelemahan dari tonus otot tidak teratur Insani, U., Supriatun, E., \& Ratnaningsih, A. / Efektivitas latihan Kegel dalam penurunan... Hal 22 dari 57 
Jurnal Ilmu Keperawatan Medial Bedah 1 (2), Desember 2018, 1-57

ISSN 2338-2058 (print), ISSN 2621-2986 (online)

kandung kemih dan terjadinya kontraksi yang tidak teratur akan menyebabkan risiko terjadinya infeksi saluran perkemihan meningkat (Nursalam, 2008). Menurut Nugroho (2008), mengompol tidak hanya menimbulkan masalah kebersihan seperti penyakit kulit, dekubitus dan bau yang tidak sedap, namun lebih dari itu, dapat pula mengakibatkan perasaan rendah diri dan isolasi.

Latihan Kegel atau latihan pergerakan pada panggul dianjurkan untuk mereka yang mengalami inkontinensia. Otot-otot yang terlibat dapat diidentifikasi dengan cara memberitahukan pasien untuk menghentikan aliran urin pada pertengahan pancaran. Latihan Kegel dilakukan dengan cara mengontraksikan dan merelaksasikan otot-otot sfingter ini 4-5 kali perhari dan lakukan pengulangan sebanyak 15 kali latihan, pada waktu makan dan waktu tidur merupakan jadwal yang mudah diingat. Peningkatan dapat dilihat dalam waktu 4-6 minggu, dengan peningkatan maksimal selama 3 bulan (Stanley \& Beare, 2006).

Rumusan permasalahan penelitian adalah "adakah pengaruh latihan Kegel terhadap kejadian inkontinensia pada lansia?". Tujuan umumnya adalah membuktikan adanya pengaruh latihan Kegel terhadap terjadinya inkontinensia pada lansia. Tujuan khususnya adalah mengidentifikasi karakteristik responden, mengidentifikasi kemampuan lansia dalam melakukan latihan Kegel, dan mengetahui adanya pengaruh latihan Kegel terhadap penurunan kejadian inkontinensia urin khususnya pada lansia yang tinggal di unit pelayanan sosial lansia Purbo Yuwono Klampok Brebes.

\section{METODE PENELITIAN}

\section{Jenis Penelitian}

Jenis penelitian yang digunakan adalah kuantitatif korelasi. Dengan variabel latihan Kegel dan kejadian inkontinensia pada lansia. Poupulasinya adalah semua lansia usia lebih dari 60 tahun yang tinggal di Panti Purboyuwono Klampok, Brebes. Sampel merupakan lansia yang masih memiliki tingkat kognitif bagus dan masih bisa melaksanakan aktivitas dengan mandiri. Jumlah sampel 38 pasien. Desain penelitian adalah kuasi eksperimen dengan pre post test. Sampel terlebih dahulu diberikan kuesioner mengenai kejadian inkontinensia menggunakan deskriptif berjenjang (tidak dapat mengontrol urin, sering tidak dapat mengontrol urin, kadang dapat mengontrol urin, dan selalu dapat mengontrol urin). Kemudian sampel diberikan intervensi latihan Kegel, dan dinilai pengontrolan terhadap pengeluaran urin selama 28 hari. Jenis intervensinya mengajarkan kepada lansia teknik latihan Kegel untuk menurunkan terjadinya Insani, U., Supriatun, E., \& Ratnaningsih, A. / Efektivitas latihan Kegel dalam penurunan... Hal 23 dari 57 
Jurnal Ilmu Keperawatan Medial Bedah 1 (2), Desember 2018, 1-57

ISSN 2338-2058 (print), ISSN 2621-2986 (online)

inkontinensia urin. Instrumen penelitian ini terdiri dari kuesioner demografi lansia dan kuesioner yang menggambarkan kemampuan lansia dalam mengatasi inkontinensia urin sebelum dan sesudah diberikan latihan Kegel. Uji inferensial yang dipakai adalah dengan menggunakan Uji paired t-test. Interpretasi dilakukan dengan membandingkan nilai $\mathrm{p}$ dan nilai alpha $(\alpha=0.05)$. Bila nilai $\mathrm{p} \leq \alpha$, maka keputusannya adalah Ha diterima sedangkan bila nilai $\mathrm{p}>\alpha$, maka keputusannya adalah Ha ditolak. Desain pada penelitian ini adalah desain kuasi eksperimen pre test (sebelum pasien melakukan latihan Kegel) dan post test (pasien setelah melakukan aktivitas latihan Kegel). Rancangan penelitian ini menggunakan “one group pretest - postest” dimana penelitian ini tidak menggunakan kelompok pembanding (kontrol) tetapi penelitian dilakukan dengan menguji perubahan yang terjadi sebelum dan sesudah adanya intervensi.

\section{Populasi dan Sampel}

Populasi dalam penelitian ini adalah seluruh lansia di Panti Wreda Purbo Yuwono Brebes yang berusia $\geq 60$ tahun dan memiliki tingkat kognitif bagus dan masih bisa melaksanakan aktivitas dengan mandiri. Jumlah populasi adalah 41 lansia. Pada penelitian ini, sampel menggunakan total sampling. Total sampling adalah teknik pengambilan sampel dengan menyertakan seluruh lansia yang ada di Unit Pelayanan Sosial Lansia Purbo Yuwono Brebes. Dengan kriteria inklusi adalah lansia dengan dengan keluhan inkontinensia urin. Kriteria eksklusi adalah lansia yang tidak bisa bicara dan mendengar, lansia yang mengalami tirah baring total, lansia yang tidak bersedia menjadi responden, lansia yang memiliki masalah psikologis dan kognitif, dan lansia yang mengkonsumsi obat-obatan.

\section{Definisi Operasional}

Latihan Kegel adalah tehnik latihan yang diajarkan oleh peneliti untuk membantu meningkatkan kontraksi otot-otot panggul untuk menurunkan terjadinya inkontinensia urin. Alat ukur yang digunakan adalah prosedur latihan Kegel, yang berisi jadwal pelatihan rutin latihan Kegel dan lembar observasi kejadian inkontinensia urin. Latihan Kegel dilakukan 5 kali dalam sehari, kemudian dilakukan observasi adanya penurunan inkontinensia urin. Data mengenai kejadian inkontinensia urin didapatkan dengan observasi dan wawancara. Data disajikan dalam bentuk deskiripsi berjenjang, yaitu : tidak dapat mengontrol urin sepanjang hari (0), jarang dapat

Insani, U., Supriatun, E., \& Ratnaningsih, A. / Efektivitas latihan Kegel dalam penurunan... Hal 24 dari 57 
Jurnal Ilmu Keperawatan Medial Bedah 1 (2), Desember 2018, 1-57

ISSN 2338-2058 (print), ISSN 2621-2986 (online)

mengontrol urin sepanjang hari (1), kadang-kadang dapat mengontrol urin (2), sering dapat mengontrol urin (3), dan selalu dapat mengontrol urin (4).

\section{Analisa Data}

a. Analisa Univariat

Pada penelitian ini penggunaan analisa univariat dilakukan untuk membuat skala persentase pada data demografi responden.

b. Analisa Bivariat

Analisa bivariat digunakan untuk menganalisis perbedaan intensitas inkontinensia urin sebelum dan sesudah dilakukan latihan Kegel. Adapun uji inferensial yang dipakai adalah dengan menggunakan uji paired t-test. Sebelumnya uji paired t-test, dilakukan uji normalitas data yaitu membandingkan nilai skewness dengan standar error. Hasil uji tersebut diketahui bahwa semua data terdistribusi normal.

\section{HASIL DAN PEMBAHASAN}

Penelitian ini dilakukan di Panti Purbo Yuwono Klampok Brebes. Jumlah lansia yang ada di Panti adalah 41 orang. Saat dilakukan penelitian, ada 3 responden yang dimasukkan dalam kriteria eksklusi karena terjadi kelemahan kognitif dan tidak dapat berkomunikasi dengan baik. Sehingga jumlah responden yang masuk kriteria inklusi adalah 38 lansia. Sebagian besar responden mengeluhkan adanya masalah pada pengontrolan urin keluar.

Tabel 1

Distribusi Kemampuan Lansia dalam Pengontrolan Eliminasi Urin Pre Latihan Kegel di Panti Purbo Yuwono Klampok Brebes, Tahun 2015 ( $\mathrm{n}=38$ )

\begin{tabular}{ccc}
\hline Pengontrolan Eliminasi Urin & Frekuensi (f) & Persentase (\%) \\
\hline Tidak dapat & 25 & 65,79 \\
Jarang & 4 & 10,53 \\
Kadang-kadang & 8 & 21,05 \\
Sering & 1 & 2,63 \\
Selalu & 0 & 0 \\
\hline Jumlah & 38 & \multirow{2}{*}{100} \\
\end{tabular}

Tabel 1 menunjukkan sebelum dilakukan latihan Kegel sebagian besar lansia mengalami masalah pada pengontrolan urin. Lansia yang mengeluhkan tidak dapat mengontrol urin Insani, U., Supriatun, E., \& Ratnaningsih, A. / Efektivitas latihan Kegel dalam penurunan... Hal 25 dari 57 
Jurnal Ilmu Keperawatan Medial Bedah 1 (2), Desember 2018, 1-57

ISSN 2338-2058 (print), ISSN 2621-2986 (online)

sejumlah 25 lansia (65,79\%), mengeluhkan jarang dapat mengontrol urin sejumlah 4 lansia (10,53\%), mengeluhkan kadang dapat mengontrol urin sejumlah 8 lansia (21,05\%), dan sering dapat mengontrol urin sejumlah 1 lansia (2,63\%). Masalah inkontinensia urin yang dialami pada sebagian responden berkaitan erat dengan proses penuaan yang mempengaruhi fungsi tubuh.

Tabel 2

Distribusi Kemampuan Lansia dalam Pengontrolan Eliminasi Urin Post Latihan Kegel di Panti Purbo Yuwono Klampok Brebes, Tahun 2015 (n=38)

\begin{tabular}{lcc}
\hline \multicolumn{1}{c}{ Pengontrolan Eliminasi Urin } & Frekuensi (f) & Persentase (\%) \\
\hline Tidak dapat & 0 & 0 \\
Jarang & 2 & 5,26 \\
Kadang-kadang & 12 & 31,58 \\
Sering & 24 & 63,16 \\
Selalu & 0 & 0 \\
\hline \multicolumn{1}{c}{ Jumlah } & 38 & 100 \\
\hline
\end{tabular}

Berdasarkan tabel 2, setelah dilakukan latihan Kegel secara rutin setiap hari ada 24 lansia $(63,16 \%)$ yang menyatakan sering dapat mengontrol urin,12 lansia $(31,58 \%)$ yang menyatakan kadang-kadang dapat mengontrol urin, dan 2 lansia (5,26\%) yang masih jarang dapat mengontrol urin.

Langkah selanjutnya, sebelum membandingkan kejadian inkontinensia pada lansia sebelum dan sesudah latihan Kegel dilakukan uji normalitas untuk mengetahui data berdistribusi normal atau tidak.

Tabel 3

Hasil Uji Normalitas Kemampuan Mengontrol Eliminasi Urin Lansia di Panti Purbo Yuwono Klampok Brebes, Tahun $2015(\mathrm{n}=38)$

\begin{tabular}{cccc}
\hline Variabel & SD & Standart Errorr & Rasio Skewness \\
\hline Kemampuan & 0,916 & 0,149 & 6,147 \\
$\begin{array}{c}\text { Mengontrol Eliminasi } \\
\text { Urin Pre Latihan }\end{array}$ & & & \\
\hline
\end{tabular}

Hasil uji normalitas menentukan uji yang akan digunakan pada tahapan analisis bivariat. Hasil uji normalitas kemampuan mengontrol urin lansia pre latihan menunjukkan data tidak normal dimana rasio skewness lebih dari 2 sehingga uji statistik yang digunakan one sample ttest.

Insani, U., Supriatun, E., \& Ratnaningsih, A. / Efektivitas latihan Kegel dalam penurunan... Hal 26 dari 57 
Tabel 4

Hasil Uji Statistik Pengaruh Latihan Kegel terhadap Kejadian Inkontinensia pada Lansia di Panti Purbo Yuwono Klampok Brebes, Tahun 2015 ( $\mathrm{n}=38)$

\begin{tabular}{cccc}
\hline Periode & Mean & SD & p-value \\
\hline Pre test & 1,61 & 0,916 & \multirow{2}{*}{0,000} \\
\hline Post test & 3,58 & 0,599 & \\
\hline
\end{tabular}

Uji Statistik menggunakan one sample t-test menunjukkan signifikansi 0,000. Nilai signifikansi $0,000 \leq 0,05$, sehingga Ha diterima. Hal ini berarti terjadi penurunan kejadian inkontinensia pada lansia setelah dilakukan latihan Kegel, ditandai dengan adanya peningkatan kemampuan kontrol urin lansia.

\section{Pembahasan}

Data kemampuan lansia dalam pengontrolan urin saat pre latihan Kegel menunjukkan 25 lansia dari 38 lansia mengeluhkan tidak dapat mengontrol urin (65,79\%). Data tersebut menunjukkan bahwa sebagian besar lansia mengeluhkan kejadian inkontinensia urin. Perubahan akibat proses menua lansia terhadap sistim genitourinaria salah satunya terjadi pada kandung kemih. Tonus otot kandung kemih menghilang dan terjadi gangguan pengosongan kandung kemih dan kapasitas kandung kemih menurun. Keluhan yang umumnya terjadi adalah peningkatan frekuensi miksi, nokturia, dan retensi urin. Kejadian ini dapat menyebabkan infeksi, urgensi, dan inkontinensia. Kejadian inkontinensia dapat terjadi saat lansia batuk, tertawa, bersin, dan mengangkat benda berat (Dewi, 2015).

Menurut penelitian Pereira, Escobar, \& Driusso (2012) menyatakan bahwa tingginya prevalensi inkontinensia urin yang terjadi pada wanita yang lebih tua, bisa disebabkan oleh jumlah efek hypoestrogenisme yang terjadi setelah menopause dan akibat dari proses penuaan. Defisiensi fungsi sfingter yang disebabkan faktor penuaan seperti perubahan hormonal dan terjadinya cedera syaraf dapat menyebabkan inkontinensia urin (Eder, 2014). Oleh karena itu, penguatan otot dasar panggul akan efektif dalam pengobatan inkontinensia urin pada wanita.

Penelitian yang dilakukan oleh Jahromi, Talebizadeh, \& Mirzaei (2014) latihan otot pelvic melalui latihan Kegel merupakan suatu mekanisme pemberdayaan bagi wanita yang tidak Insani, U., Supriatun, E., \& Ratnaningsih, A. / Efektivitas latihan Kegel dalam penurunan... Hal 27 dari 57 
Jurnal Ilmu Keperawatan Medial Bedah 1 (2), Desember 2018, 1-57

ISSN 2338-2058 (print), ISSN 2621-2986 (online)

mampu dalam meningkatkan kualitasnya hidup dan harga dirinya, jadi dianjurkan agar program latihan ini digunakan di pusat perawatan kesehatan lansia yang didampingi oleh pembimbing/pembina, sebagai faktor untuk meningkatkan promosi kesehatan lansia yang menderita inkontinensia urin. Hasil penelitian ini menyatakan distribusi perubahan kejadian inkontinensia urin setelah dilakukan latihan Kegel di Panti Purbo Yuwono Klampok Brebes Tahun 2015, diketahui bahwa 33 lansia mengalami peningkatan dalam mengontrol urin (86.84\%), hanya 5 lansia yang tetap mengalami inkontinensia urin (13.16\%) yang mana didominasi oleh lansia dengan jenis kelamin perempuan. Yavuzcan et al. (2013) menjelaskan bahwa sebesar $23 \%$ responden wanita yang berusia 50 tahun ke atas dan $15 \%$ responden wanita dengan manopause dapat mengalami penurunan inkontinensia urin setelah dilakukan latihan Kegel.

Pencapaian hasil berupa peningkatan kemampuan kontrol urin setelah diberikan latihan Kegel dapat disebut independent continentia. Pencapaian hasil tersebut membutuhkan waktu agar inkontinensia urin dapat tercapai. Peneliti mengestimasikan waktu untuk independent continentia selama 4 minggu dimana latihan dilakukan sehari 5 kali dengan waktu pelaksanaan latihan Kegel yaitu saat makan pagi, makan siang, makan malam, menjelang tidur dan saat bangun tidur. Pemilihan waktu ini diharapkan dapat memudahkan lansia untuk mengingatnya. Lansia melakukan latihan Kegel sebanyak 10 kali dengan menahan kontraksi otot selama 5 detik. Latihan tersebut dilakukan secara berkelompok masing-masing ruangan secara terpisah, Sedangkan, pada penelitian yang dilakukan Jahromi, Talebizad \& Mirzaei (2015) latihan Kegel dilakukan sehari sebanyak 3 kali, dengan jumlah latihan sebanyak 8-12 kali dan menahan kontraksi otot selama 6-8 detik.

Penelitian yang dilakukan oleh Jahromi, Talebizad \& Mirzaei (2015) dilakukan selama 2 bulan sehingga adanya penurunan inkontinensia urin yang lebih signifikan. Sementara penelitian ini hanya dilakukan selama 1 bulan. Perubahan yang dirasakan responden penelitian ini yaitu adanya peningkatan kesadaran dari sensasi berkemih sehingga lansia dapat segera menahan dan berupaya berkemih pada tempatnya. Namun, penelitian yang dilakuakan oleh Jahromi, Talebizad \& Mirzaei (2015) menunjukkan adanya peningkatan tingkat self esteem atau percaya diri karena dapat mengontrol stres inkontinensia urin baik ketika tertawa ataupun posisi tubuh lainnya seperti duduk atau berdiri.

Insani, U., Supriatun, E., \& Ratnaningsih, A. / Efektivitas latihan Kegel dalam penurunan... Hal 28 dari 57 
Jurnal IImu Keperawatan Medial Bedah 1 (2), Desember 2018, 1-57

ISSN 2338-2058 (print), ISSN 2621-2986 (online)

Penelitian ini juga pernah dilakukan oleh Widyaningsih (2009) dengan judul Pengaruh latihan Kegel terhadap Frekuensi Inkontinensia Urin pada Lansia di Panti Wreda Pucang Gading Semarang. Hasil penelitian menunjukkan, bahwa setelah dilakukan latihan Kegel terjadi penurunan frekuensi inkotinensia urin sebesar 21,6\% dari 10,043 kali menjadi 7,871 kali. Dari hasil uji independent t-test didapatkan nilai p sebesar 0,000 sehingga ada pengaruh latihan Kegel terhadap frekuensi inkontinensia urin pada lansia di Panti Wreda Pucang Gading Semarang.

Penelitian lainnya juga dilakukan oleh Setyawati (2008) yang dilakukan di Panti Wredha Wilayah Semarang dengan kombinasi latihan Kegel dengan bladder training untuk menurunkan episode inkontinensia pada lansia didapatkan hasil uji statistik dengan nilai $\mathrm{p}=0,0001$ maka dapat disimpulkan bahwa pada alpha 5\% terlihat ada perbedaan yang signifikan frekuensi inkontinensia urin antara responden kelompok perlakuan dan responden kelompok kontrol setelah dilakukan intervensi.

Cha \& Jang (2016) menjelaskan bahwa latihan Kegel meningkatkan sensor sfingter dalam konstriksi dan pengeluaran cairan yang mungkin keluar dari sfingter. Latihan Kegel menjadi aktifitas yang dibutuhkan untuk meningkatkan stimulus panggul bagian bawah, khususnya pada lansia wanita. Hal tersebut perlu dilakukan secara terjadwal untuk mengevaluasi penurunan inkontinensia.

Penelitian yang dilakukan oleh Park \& Kang (2014) menyatakan bahwa Kegel merupakan pengobatan dalam bentuk latihan yang hemat biayanya, bisa dilakukan secara mandiri. Pasien bisa melakukannya kapan saja, dimana saja, bisa dilakukan saat melakukan pekerjaan lain, dan tanpa kunjungan rutin ke rumah sakit sehingga intervensi latihan panggul dengan Kegel ini bisa disebut dengan intervensi ekonomis. Intervensi latihan Kegel di Panti Purbo Yuwono Klampok Brebes dilakukan dalam keadaan lansia menjelang tidur, bangun tidur dan pada saat pagi hari (saat sarapan pagi), siang dan sore hari.

\section{KESIMPULAN}

Setelah dilakukan uji statistik didapatkan hasil adanya pengaruh latihan Kegel (Kegel exercise) terhadap penurunan terjadinya inkontinensia urin pada lansia di Panti Wreda Purbo Yuwono Brebes. Intervensi latihan Kegel di Panti Purbo Yuwono Klampok Brebes dilakukan dalam keadaan lansia menjelang tidur, bangun tidur dan pada saat pagi hari (saat sarapan pagi), Insani, U., Supriatun, E., \& Ratnaningsih, A. / Efektivitas latihan Kegel dalam penurunan... Hal 29 dari 57 
Jurnal Ilmu Keperawatan Medial Bedah 1 (2), Desember 2018, 1-57

ISSN 2338-2058 (print), ISSN 2621-2986 (online)

siang dan sore hari. Hal ini terbukti efektif dalam menurunkan terjadinya inkontinensia pada lansia.

Latihan Kegel dapat menurunkan intensitas terjadinya inkontinensia urin maka sebaiknya Panti Wreda dapat membuat protap yang dilakukan secara konsisten tentang latihan Kegel dan selalu mensosialisasikan manfaat latihan Kegel kepada lansia, sehingga membantu lansia menurunkan efek inkontinensia urin yang dialami (seperti bau yang tidak sedap dan adanya perasaan kotor) dan memotivasi untuk melakukan latihan Kegel secara rutin. Penelitian selanjutnya dapat melakukan penelitian inkontinensia urin pada lansia di setting keluarga agar dapat mengetahui faktor lain dapat meningkatkan efektivitas latihan Kegel terhadap inkontinensia urin. Penelitian selanjutnya juga dapat melakukan latihan Kegel lebih lama lagi untuk menunjukkan hasil yang lebih signifikan.

\section{DAFTAR PUSTAKA}

Aslan, E., Komurcu, N., Beji, N.K., \& Yalcin, O. (2008). Bladder training and Kegel exercises for women with urinary complaints living in a rest home. Gerontology 54.4 (Jun 2008): 224-31. ProQuest Nursing \& Allied Health Source.

Busuttil-Leaver, R. (2008). Incontinence: a proactive approach. Practice Nurse 35.6 (Mar 28, 2008): 30-32. ProQuest Nursing \& Allied Health Source.

Cha, J., \& Jang, J. (2016). Pelvic floor muscle exercise system designed for the prevention of urinary incontinence. International Information Institute (Tokyo). Information, 19(5), 14311437. Retrieved from https://search.proquest.com/docview/1799903894?accountid=17242.

Eder, S.E. (2014). Evaluation of the EmbaGYN(TM) pelvic floor muscle stimulator in addition to Kegel exercises for the treatment of female stress urinary incontinence: A prospective, open-label, multicenter, single-arm study. Women's Health, 10(1), 17-27. http://dx.doi.org/10.2217/whe.13.67 Retrieved from https://search.proquest.com/docview/1467087780?accountid=17242.

Grimshaw, R., Jain, P., \& Latthe, P. (2012). Management of mixed urinary incontinence. Women's Health 8.5 (Sep 2012): 567-77. ProQuest Nursing \& Allied Health Source.

Jahromi, M. K., Talebizadeh, M., \& Mirzaei, M. (2015). The effect of pelvic muscle exercises on urinary incontinency and self-esteem of elderly females with stress urinary incontinency, 2013. Global Journal of Health Science, 7(2), 71.

Nugroho, W. (2008). Keperawatan gerontik dan geriatri. (Edisi 3). Jakarta : EGC.

Insani, U., Supriatun, E., \& Ratnaningsih, A. / Efektivitas latihan Kegel dalam penurunan... Hal 30 dari 57 
Jurnal IImu Keperawatan Medial Bedah 1 (2), Desember 2018, 1-57

ISSN 2338-2058 (print), ISSN 2621-2986 (online)

Nursalam. (2008). Asuhan keperawatan pada pasien dengan gangguan sistem perkemihan. Jakarta : Salemba Medika.

Nursalam. (2003). Konsep dan penerapan metodologi penelitian keperawatan. Jakarta : Salemba Medika.

Park, S., \& Kang, C. (2014). Effect of Kegel exercises on the management of female stress urinary incontinence : a systematic review of randomized controlled trials.

Pereira, V. S., Escobar, A. C., \& Driusso, P. (2012). Effects of physical therapy in older women with urinary incontinence: a systematic review. Revista Brasileira de Fisioterapia (São Carlos (São Paulo, Brazil)), 16(6), 463-8. http://doi.org/10.1590/S141335552012005000050 .

Pranarka. (2001). Ilmu penyakit dalam. Jilid 1. Edisi 3. Jakarta : FKUI.

Setiati. (2001). Majalah kedokteran Indonesia. Volume 51. Jakarta : FKUI.

Setyawati, R. 2008. Efek kombinasi Kegel's exercise dan bladder training dalam menurunkan episode inkontinensia urin pada lansia di Panti Wredha Wilayah Semarang.http://lib.ui.ac.id/file?file=digital/2016-10/20438031-Retno\%20Setyawati.pdf.

Stanley, M., \& Beare, P.G. (2006). Buku ajar keperawatan gerontik. Edisi 2. Jakarta : EGC.

Widyaningsih. (2009). Pengaruh latihan Kegel terhadap frekuensi inkontinensia urin pada lansia di Panti Wreda Pucang Gading Semarang. http://repository.unimus.ac.id/2009/pengaruhlatihanKegelterhadapfrekuensiinkontinensiaurinpadalansia.

Yavuzcan, A., Yildiz, G., Üstün, Y., Altintas, R., Çaglar, M., Yildiz, P., \& Kumru, S. (2013). Influence of age, menopause, pelvic muscle exercises, urethral hypermobility and concomitant surgery on the outcomes after the transobturator tape procedure (factors effecting TOT outcomes). Przeglad Menopauzalny, 17(2), 105. http://dx.doi.org/10.5114/pm.2013.35063 Retrieved from https://search.proquest.com/docview/1366667570?accountid=17242.

Insani, U., Supriatun, E., \& Ratnaningsih, A. / Efektivitas latihan Kegel dalam penurunan... Hal 31 dari 57 